\title{
Message from the new editor-in-chief
}

\author{
Hisashi Okamoto ${ }^{1}$
}

During the active leadership of Professor Masayasu Mimura as the editor-in-chief of the Japan Journal of Industrial and Applied Mathematics (JJIAM), our journal has evolved to become a truly international journal. His contribution to this journal is so large that I do not have the proper words to express my admiration for him. As the new editor-in-chief I declare that Professor Mimura's policy and enthusiasm will be maintained. On the other hand, I will not shrink from reforms that are necessary for dealing with the constantly changing world of academic publishing.

My deep appreciation also goes to Professor Kokichi Sugihara and Professor Kazuo Murota for their long-time service to JJIAM. Lastly, I sincerely thank the retiring associate editors and advisers. Although I do not name them here, I do understand that JJIAM has achieved its high status thanks to their efforts.

Hisashi Okamoto

okamoto@kurims.kyoto-u.ac.jp

1 Research Institute for Mathematical Sciences, Kyoto University, Kyoto 606-8502, Japan 